\title{
Análise de aspectos pedagógicos da educação profissional técnica do Instituto Federal de Minas Gerais
}

\author{
Analysis of pedagogical issues of the secondary technical vocational education of the Federal Institute
} of Minas Gerais

Walas Leonardo de Oliveira - Instituto Federal de Minas Gerais - walas.oliveira@ifmg.edu.br

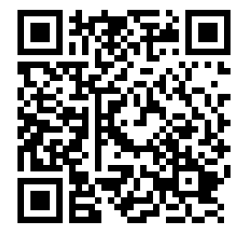

Este artigo apresenta parte dos resultados de uma E pesquisa desenvolvida no Instituto Federal de Educação, Ciência e Tecnologia de Minas Gerais (IFMG) no primeiro semestre de 2012, na qual foi realizada uma avaliação dos cursos técnicos dos novos campi ${ }^{1}$ do IFMG.

\footnotetext{
1 Para preservar a identidade dos campi investigados, neste trabalho seus nomes verdadeiros foram substituídos por nomes fictícios: Alfa, Beta, Asus, Ômega e Pégaso.
}

Resumo: O objetivo deste estudo foi avaliar alguns aspectos pedagógicos da educação profissional técnica de nível médio dos novos campi do Instituto Federal de Educação, Ciência e Tecnologia de Minas Gerais (IFMG). Este trabalho, resultado de uma pesquisa realizada no IFMG, investigou oito eixos temáticos: a) Instalações, materiais e equipamentos, b) Relação do curso com a missão institucional do IFMG e com o setor produtivo, c) Organização didático-pedagógica, d) Corpo docente e administrativo, e) Formação inicial e continuada, f) Avaliação, g) Evasão e reprovação e h) Estágio e Trabalho de Conclusão de Curso (TCC). Desses oito eixos, três foram escolhidos para o presente trabalho: a) Organização didático-pedagógica, b) Formação inicial e continuada e c) Estágio e Trabalho de Conclusão de Curso. A metodologia utilizada foi a pesquisa qualitativa, e a coleta de dados foi realizada a partir de entrevistas semiestruturadas com os gestores dos campi. Os dados coletados foram analisados com base em produções científicas sobre educação profissional no Brasil, especialmente obras de autores marxistas. Os resultados indicam que os três elementos investigados, apesar de terem recebido notas satisfatórias, especialmente do ponto de vista quantitativo, apresentam pontos negativos em todos os campi, evidenciando que melhorias podem e devem ser realizadas.

Palavras-chave: organização didático-pedagógica, formação inicial e continuada, trabalho de conclusão de curso, estágio, avaliação da educação profissional técnica.

\begin{abstract}
The objective of this study was to evaluate some pedagogical issues of the professional technical high-school education in new campuses of Federal Institute of Education, Science and Technology of Minas Gerais (IFMG). This work, result of a research at IFMG, investigated eight themes: a) the school facilities, materials and equipment, b) the relation between the courses, the institutional mission and the productive sector, c) the didactic-pedagogical organization, d) teaching and administrative staff, e) the initial and continuing training of teachers, f) the evaluation, g) the school dropout and school failure, $h$ ) the internship and the course final paper. Three between these eight themes were chosen for this article: a) the didactic-pedagogical organization, b) the initial and continuing training of teachers, c) the internship and the course final paper. The methodology used was qualitative research and the data collection was made from semi-structured interviews with the managers of the campuses. The collected data were analyzed based on scientific production about professional education in Brazil, mainly with works of Marxist authors. The results indicate that the three investigated elements, despite having satisfactory grades especially from quantitative point of view, have negative items on all campuses, showing the need of improvement.
\end{abstract}

Keywords: didactic-pedagogical organization, initial and continuing training, end-ofcourse written paper, internship, evaluation of secondary technical vocational education. 
(TCC). No entanto, devido aos limites impostos para a escrita de um artigo científico e para não se cair na superficialidade, optou-se por trabalhar aqui apenas três desses oito eixos: a) Organização didático-pedagógica, b) Formação inicial e continuada de professores e técnicos administrativos e c) Estágio e Trabalho de Conclusão de Curso. Esses três eixos foram escolhidos por serem estratégicos para a elevação da qualidade da educação profissional técnica no Brasil e por representarem desafios para essa modalidade de ensino. Nesse sentido, por exemplo, Dore e Luscher (2011) apontam que a organização didático-pedagógica, consubstanciada nas práticas escolares e pedagógicas, é um elemento influenciador na evasão escolar de alunos da educação profissional técnica.

A formação inicial e continuada de professores e técnicos administrativos, especialmente a formação inicial de professores, segundo Machado (2011), Urbanetz (2012), Filho e Shiroma (2011), é um dos pontos problemáticos da educação profissional brasileira e não tem, até o momento, recebido a devida importância em termos de políticas educacionais. Aqui, está se entendendo por formação inicial aquela realizada antes da entrada do servidor no IFMG, principalmente a realizada em cursos de graduação, como a graduação tecnológica, o bacharelado ou a própria licenciatura. Já a formação continuada está sendo entendida por todo tipo de formação que ocorre quando o professor ou técnico administrativo já se encontra em serviço: palestras, seminários, congressos, cursos de aperfeiçoamento, cursos de especialização etc.

E, por fim, o estágio e o TCC foram escolhidos para esta discussão por tratar-se de atividades importantes para a formação do aluno, especialmente no sentido de sintetizar teoria e prática. O estágio, especialmente, de acordo com Felício e Oliveira (2008), se bem fundamentado, estruturado e orientado, configura-se como um momento de relevante importância no processo de formação prática, principalmente para futuros professores.

O objetivo geral da pesquisa foi avaliar as atuais condições de funcionamento dos cursos técnicos dos novos campi do IFMG no que se refere a aspectos pedagógicos.

O estudo se justifica, uma vez que o conhecimento aprofundado dos cursos técnicos em funcionamento nos novos campi do IFMG é fundamental para o processo de constituição desses campi. Nesse sentido, os resultados obtidos podem ser muito úteis aos gestores para planejarem e executarem ações que visem à melhoria da qualidade da educação oferecida em cada curso técnico. Além disso, como os Institutos Federais são instituições recém-criadas no Brasil, ainda são escassos os trabalhos científicos que abordam questões relacionadas a essas instituições.
Portanto, a pesquisa realizada poderá contribuir para o avanço do conhecimento científico sobre a nova configuração da Educação Profissional no país, oferecendo subsídios a outros pesquisadores interessados em investigar temáticas similares no âmbito dos Institutos Federais.

Tendo em vista a natureza do problema deste estudo e considerando que esse problema requer coleta de informações quantificáveis e, ao mesmo tempo, requer aprofundamento dos dados coletados com entrevistas, fez-se necessário realizar pesquisa qualitativa, mas com caráter também quantitativo. Nesse sentido, para o desenvolvimento da pesquisa, foram realizadas visitas aos novos campi do IFMG, nas quais foram conduzidas entrevistas semiestruturadas com os gestores dos cursos técnicos: diretor-geral, diretor de ensino, coordenador de curso e pedagogo.

\section{Da Escola de Aprendizes Artífices AOS INSTITUTOS FEDERAIS}

Os Institutos Federais de Educação, Ciência e Tecnologia foram criados pela Lei $n^{\circ} 11.892 / 2008$ e configuram-se como instituições de educação superior, básica e profissional, com estrutura multicampi, especializados na oferta de educação profissional e tecnológica nas diferentes modalidades de ensino (BRASIL, 2008b).

Os Institutos Federais fazem parte da Rede Federal de Educação Profissional, Científica e Tecnológica, rede essa que começou a se desenvolver a partir de 1909 com as chamadas "Escolas de Aprendizes Artífices", criadas na época pelo Decreto $n^{\circ} 7.566$ do então presidente da República, Nilo Procópio Peçanha. De acordo com Caldas et al. (2011), a princípio foram criadas dezenove Escolas de Aprendizes Artífices, todas subordinadas ao Ministério dos Negócios da Agricultura, Indústria e Comércio. Essas escolas, segundo Silva (2010), em um primeiro momento não tinham relação com o processo de produção e com a industrialização do país, ainda incipientes. Tais escolas possuíam, na verdade, o papel de retirar das ruas os chamados "desvalidos da sorte", como pobres, órfãos e indigentes e dar-lhes uma formação moral. Segundo Neto (2009), seguindo o Decreto presidencial, a primeira escola de aprendizes artífices do Brasil foi instalada em Aracaju (Sergipe), em 1911. A partir de 1930, ainda segundo Neto (2009), mudanças socioeconômicas e políticas, verificadas na Era Vargas (1930-1945), impulsionaram tanto a indústria de base como a educação profissionalizante, consideradas pilares do progresso nacional. Nesse contexto, as Escolas 
de Aprendizes Artífices passaram a ser de responsabilidade do recém-criado Ministério da Educação e Saúde Pública e foram denominadas, em 1937, de "Liceus Industriais".

Conforme Neto (2009), do final da década de trinta em diante, houve um sensível aumento nos investimentos na área da educação profissional, exigido tanto pela crescente industrialização durante a Segunda Guerra Mundial (19391945) quanto pelas transformações urbanas por que passava o país. Nessa conjuntura, em 1942 os liceus passaram a ser chamados de "Escolas industriais e técnicas", tendo seus cursos já considerados como de nível médio. Nesse período, iniciou-se formalmente o processo de vinculação do ensino industrial à estrutura do ensino do país, uma vez que os alunos formados nos cursos técnicos ficavam autorizados a ingressar no ensino superior em área equivalente à da sua formação.

A partir de 1959, iniciou-se o processo de transformação das Escolas Industriais e Técnicas em autarquias. Nesse momento, as "Escolas industriais e técnicas" ganham autonomia didática e de gestão e passam a ser denominadas Escolas Técnicas Federais. Com isso, intensificam gradativamente a formação de técnicos: mão de obra indispensável diante da aceleração do processo de industrialização.

De acordo com Brasil (2010), em 1971, a Lei de Diretrizes e Bases da Educação Brasileira, Lei 5.692 de 1971, transformou, de maneira compulsória, todo currículo do segundo grau em técnico profissional. O objetivo dessa Lei era formar técnicos em caráter de urgência. Naquele momento, as Escolas Técnicas Federais aumentaram o número de matrículas e implantaram novos cursos. Em 1978, três Escolas Técnicas Federais (Paraná, Minas Gerais e Rio de Janeiro) foram transformadas em Centros Federais de Educação Tecnológica. Essa mudança conferiu a essas instituições a responsabilidade de atuarem em nível mais elevado de formação, exigência decorrente do padrão de produção. Em 1994, a Lei Federal no 8.984 instituiu no país o Sistema Nacional de Educação Tecnológica. Essa medida anunciou a transformação das Escolas Técnicas Federais em Centros Federais de Educação Tecnológica (CEFETs) e abriu caminho para que as Escolas Agrotécnicas Federais fossem integradas a esse processo. Esse foi o marco inicial para a constituição, em grande número, dos CEFETs. No entanto, a implantação de novos CEFETs só ocorreu efetivamente a partir de 1999. Nesse momento, o governo brasileiro firmou uma parceria com o Banco Interamericano de Desenvolvimento (BID) para o desenvolvimento do Programa de Expansão da Educação Profissional (PROEP).

Conforme Brasil (2010), em 2003 foram editadas novas medidas para a educação profissional e tecnológica. Houve a substituição do Decreto $n^{\circ} 2.208 / 97$ pelo Decreto $n^{\circ}$ 5.154/04, o qual eliminou os entraves estabelecidos por aquele, que se traduziam numa série de restrições na organização curricular e pedagógica e na oferta dos cursos técnicos. A partir desse ano, no contexto da expansão e valorização da Rede Federal de Educação Profissional e Tecnológica, o governo Lula implementou uma série de medidas para levar educação profissional pública, gratuita e de qualidade para todo o país. Esse projeto pode ser dividido em duas fases: a primeira, iniciada em 2006, teve como objetivo levar as escolas federais de educação profissional para cidades e regiões onde ainda não existiam tais instituições. A segunda fase, iniciada em 2007, almejava implantar 150 novas unidades de ensino em três anos (BRASIL, 2010).

Já em 2004, a Rede Federal de Educação Tecnológica (formada pelos Centros Federais de Educação Tecnológica, Escolas Agrotécnicas Federais, Escola Técnica Federal de Palmas/TO e Escolas Técnicas vinculadas às Universidades Federais) ganhou autonomia para a criação e implantação de cursos em todos os níveis da educação profissional e tecnológica.

Atualmente, segundo o próprio Ministério da Educação² (MEC), a Rede Federal de Educação Profissional e Tecnológica possui 354 unidades. Com outras 208 novas escolas, o MEC prevê 562 unidades até o final de 2014, sendo a maioria Institutos Federais.

O objetivo do governo com essa interiorização das escolas federais de educação profissional era promover o desenvolvimento local e regional, articulado com a melhoria do padrão de vida da população de regiões geograficamente delimitadas. Contudo, esse projeto só viria a se efetivar plenamente a partir de 2008, com a promulgação da Lei Federal $n^{\circ} 11.892$, que instituiu a Rede Federal de Educação Profissional e Tecnológica e criou os Institutos Federais de Educação, Ciência e Tecnologia (BRASIL, 2010).

A Lei no 11.892 criou 38 Institutos Federais de Educação, Ciência e Tecnologia, aproveitando-se a infraestrutura dos Centros Federais de Educação Tecnológica, das Escolas Agrotécnicas Federais e das Escolas Técnicas de algumas universidades federais.

Uma das finalidades dos Institutos Federais, segundo o art. $6^{\circ}$ da referida Lei, é "ofertar educação profissional e tecnológica, em todos os seus níveis e modalidades, formando e qualificando cidadãos com vistas na atuação profissional nos diversos setores da economia, com ênfase no desenvolvimento socioeconômico local, regional e nacional" (BRASIL, 2008b). Portanto, os Institutos Federais possuem características nunca antes observadas em outras instituições de educação profissional, especialmente: o foco no desenvolvimento local e regional e atuação em todos os níveis e modalidades da profissionalização, da formação inicial e continuada de trabalhadores à pós-graduação.

2 Disponível em: <http://redefederal.mec.gov.br/index.php?option=com content\&view=article\&id=52\&ltemid=2> Acesso em: 25 mai 2014. 


\section{Instituto Federal de Educação, Ciência e Tecnologia de Minas GERAIS}

O Instituto Federal de Educação, Ciência e Tecnologia de Minas Gerais (IFMG) nasceu da união da Escola Agrotécnica Federal de São João Evangelista, dos CEFETs de Ouro Preto e Bambuí e das Unidades de Ensino Descentralizadas (UNEDs) de Formiga e Congonhas. Até maio de 2014, era composto por doze campi: Bambuí, Betim, Congonhas, Formiga, Governador Valadares, Ouro Branco, Ouro Preto, Piumhi, Ribeirão das Neves, Sabará, Santa Luzia e São João Evangelista. Até essa data, eram, aproximadamente, 8000 alunos, distribuídos entre 74 cursos técnicos, 33 cursos superiores e 4 cursos de pós-graduação. A instituição possui, aproximadamente, 1058 servidores, sendo 568 técnicos administrativos e 490 professores ${ }^{3}$.

Além do IFMG, outros quatro Institutos Federais ${ }^{4}$ e um CEFET compõem a Rede Federal de Educação Profissional e Tecnológica no Estado de Minas Gerais.

\section{ResultAdOS: APRESENTAÇÃO E ANÁLISE}

Para a realização das entrevistas, os pesquisadores basearam-se em um instrumento que continha 39 questões para os campi que ofertavam cursos técnicos integrados e 36 para os campi que ofertavam cursos concomitantes ou subsequentes. Desse total de questões, 6 abordavam a temática organização didático-pedagógica, 3 estavam relacionadas à formação inicial e continuada e 3 questões referiam-se ao Estágio e Trabalho de Conclusão de Curso. Para esse último eixo, quando o curso não possuía trabalho de conclusão de curso, foram aplicadas apenas 2 questões. Cada resposta estava relacionada a um conceito. Os conceitos possuíam pontuação que variava de 1 a 4 , sendo que quanto mais próximo de 4 , melhores as condições educacionais. Portanto, os conceitos 1 e 2 significavam que o campus ainda não atingiu um nível satisfatório naquele indicador, e os conceitos 3 e 4 significavam que o campus já atingiu um nível satisfatório ou mais que satisfatório.

\footnotetext{
3 Fonte: Revista IFMG (especial) - Publicação do Instituto Federal de Educação, Ciência e Tecnologia de Minas Gerais e site do IFMG (www. ifmg.edu.br). Acesso em 23 de maio de 2014.

4 Os outros quatro Institutos Federais presentes em Minas Gerais são: Instituto Federal do Sudeste de Minas, Instituto Federal do Sul de Minas, Instituto Federal do Triângulo Mineiro e Instituto Federal do Norte de Minas.
}

Após a escolha da resposta de cada indicador, os gestores tiveram de justificá-las, utilizando-se, para isso, de relatos descritivos. Cada campus recebeu uma nota geral e uma nota específica para cada eixo, de 0 a 100. A nota geral obtida por cada campus era traduzida em critérios como os demonstrados na tabela abaixo:

Tabela 1 - Critérios de análise.

\begin{tabular}{l|c|c}
\multicolumn{1}{c}{$\begin{array}{c}\text { Critério de } \\
\text { análise }\end{array}$} & \multicolumn{1}{c}{ Valor } & $\begin{array}{c}\text { Resultado do } \\
\text { Campus 5 }\end{array}$ \\
Ruim & 0 a $25 \%$ & \\
\hline Razoável & 26 a $50 \%$ & \\
\hline Bom & 51 a $75 \%$ & \\
\hline Muito bom & 76 a $100 \%$ & \\
\hline
\end{tabular}

Fonte: Instrumento de avaliação dos cursos técnicos do IFMG.

A seguir, serão apresentados e analisados os resultados obtidos com a aplicação do instrumento de coleta de dados em cada um dos três eixos selecionados.

\section{ORgANIZAÇÃO DIDÁTICO-PEDAGÓGICA}

Gráfico 1 - Organização didático-pedagógica.

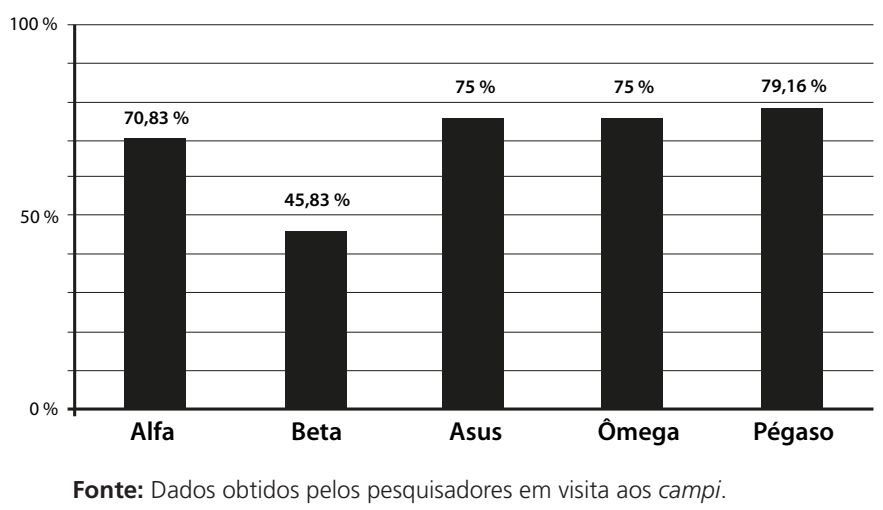

Os campi do IFMG que foram investigados obtiveram 83 pontos nesse primeiro eixo, que continha 6 questões. Dessa forma, ao se multiplicarem 04 pontos, pontuação máxima possível de ser alcançada em cada pergunta, pelo número de questões aplicadas em todos os campi, 30 questões, chega-se a um total máximo de 120 pontos. Os 83 pontos obtidos pelos campi correspondem a 69,1\% desse valor, o que pode ser representado pelo conceito "bom". Portanto, pode-se dizer que os campi do IFMG que foram investigados possuem uma boa organização didático-pedagógica.

5 Nesta coluna, marcava-se com um $\mathrm{X}$ a escala que correspondia ao resultado obtido pelo campus. 
O Campus Beta recebeu a nota $45,83 \%$ no eixo em questão. Esse resultado baixo deve-se principalmente ao fato de nessa unidade não existir aproveitamento de conhecimentos e experiências anteriores. Essa constatação é grave, visto que tal possibilidade é um direito dos alunos, previsto nos artigos 73 a 80 do Regimento de Ensino do IFMG (IFMG, 2013) e na Resolução CNE/CEB nº 06/2012 (BRASIL, 2012). As demais questões do Eixo "Organização didático-pedagógica", desse campus, também não obtiveram um bom resultado, já que todas receberam o conceito "razoável". Foram consideradas razoáveis a matriz curricular, as metodologias de ensino, a diversidade de estratégias didático-metodológicas, a interdisciplinaridade e a realização de atividades complementares.

Entre os aspectos que precisam ser melhorados, foi mencionada pelos gestores a necessidade de alterar a matriz curricular dos cursos, com a inclusão, fusão e eliminação de disciplinas, bem como de alterar as ementas e bibliografias. Sobre as metodologias de ensino, foi relatado que o corpo docente ainda é inexperiente, faltando-lhe conhecimentos sobre o trabalho com alunos adolescentes. Em relação à diversidade das estratégias didático-metodológicas (aula expositiva, aula prática, seminário, atividades em grupo etc.) em uma mesma disciplina, mencionaram que faltam aulas práticas. Quanto à interdisciplinaridade, informaram que está prevista nos planos de ensino e acontece nas visitas técnicas, mas que os trabalhos interdisciplinares ainda se encontram em fase inicial. As atividades complementares, por sua vez, precisam ser fortalecidas, especialmente no que se refere a um melhor acompanhamento da monitoria acadêmica.

Todos esses pontos negativos apresentados são graves e necessitam de resolução imediata. De acordo com Dore e Luscher (2011), são exatamente problemas como os detectados que aumentam as chances de os alunos de cursos técnicos evadirem. Em sua pesquisa, uma investigação denominada "Educação profissional e evasão escolar em Minas Gerais", as autoras constataram que questões pedagógicas possuem um peso significativo na decisão do aluno de curso técnico de abandonar a escola. Essas autoras alertam, inclusive, que as pesquisas sobre evasão e retenção na educação profissional devem voltar-se não apenas para fatores individuais dos alunos em risco de evasão e/ou retenção, mas também para questões que são de competência das próprias instituições escolares:

(...) a pesquisa sobre causas para a evasão escolar deve incluir, necessariamente, além das motivações individuais, os fatores associados à esfera de competência e de atuação da instituição escolar; por exemplo, as áreas tecnológicas em que os cursos são ofertados, as práticas pedagógicas, a programação das disciplinas, os programas de estágio e de outras práticas profissionais, os processos de avaliação, a formação docente, dentre outros aspectos (DORE e LUSCHER, 2011, p. 785).

Portanto, problemas relacionados à matriz curricular, às metodologias de ensino, à avaliação, à ausência de interdisciplinaridade, etc. devem ser tratados com seriedade pelos gestores de cursos de educação profissional técnica, sob pena de se aumentarem os índices de evasão e retenção.

O Campus Pégaso recebeu a maior nota entre os demais, principalmente devido às questões "aproveitamento de conhecimentos e experiências anteriores" e "diversidade das estratégias didático-metodológicas", que receberam o critério de análise muito bom. O campus em questão prevê esse tipo de aproveitamento no calendário escolar. Para o aproveitamento de disciplinas realizadas em outros cursos, foram analisadas as ementas e observada a carga horária da disciplina cursada. Para o aproveitamento de conhecimentos anteriores, o professor da área elabora uma avaliação e o interessado demonstra os conhecimentos já adquiridos.

Esse campus também obteve um bom resultado nas questões "matriz curricular", "metodologias de ensino" e "realização de atividades complementares". Entre os aspectos positivos dessas questões que obtiveram resultado bom, foi mencionado que houve uma recente atualização das matrizes curriculares dos cursos, inclusive com o aumento de carga horária e com a introdução das disciplinas Português e Matemática. As metodologias de ensino têm atendido bem às expectativas dos alunos, apesar de os gestores terem a intenção de incorporar o uso de simuladores nas disciplinas, valorizando atividades práticas. Sobre a diversidade de estratégias didático-metodológicas, os entrevistados informaram que, no geral, essas estratégias são diversificadas, tais como aulas expositivas, projetos, seminários etc. A respeito de atividades complementares, os entrevistados disseram que há monitorias de duas disciplinas, que já foram realizados minicursos e palestras, além de existir iniciação científica. A única questão avaliada negativamente nesse eixo foi a interdisciplinaridade. Embora existam trabalhos interdisciplinares, ainda falta o fortalecimento dessas atividades.

Portanto, é possível perceber que, mesmo com uma infraestrutura inadequada, já que, por exemplo, o Campus Pégaso funciona provisoriamente em uma escola municipal com muitos problemas físicos, é possível possuir uma organização didático-pedagógica de qualidade. Esse campus possui procedimentos didático-pedagógicos constituídos de atividades teóricas e práticas contextualizadas, bem como projetos voltados para o desenvolvimento da capacidade de resolução de problemas. 


\section{FORMAÇÃO INICIAL E CONTINUADA DE PROFESSORES E TÉCNICOS ADMINISTRATIVOS}

Esse eixo possuía três questões: índice de professores cuja graduação não se relaciona diretamente com a disciplina que leciona; formação continuada para os diretores do campus administrarem o uso de sistemas de gestão educacional; e formação continuada sobre reprovação e evasão nos cursos técnicos para os professores e técnicos administrativos que atuam no apoio ao discente. Os resultados obtidos pelos campi, nesse eixo, estão descritos no gráfico 2 .

Gráfico 2 - Formação inicial e continuada.

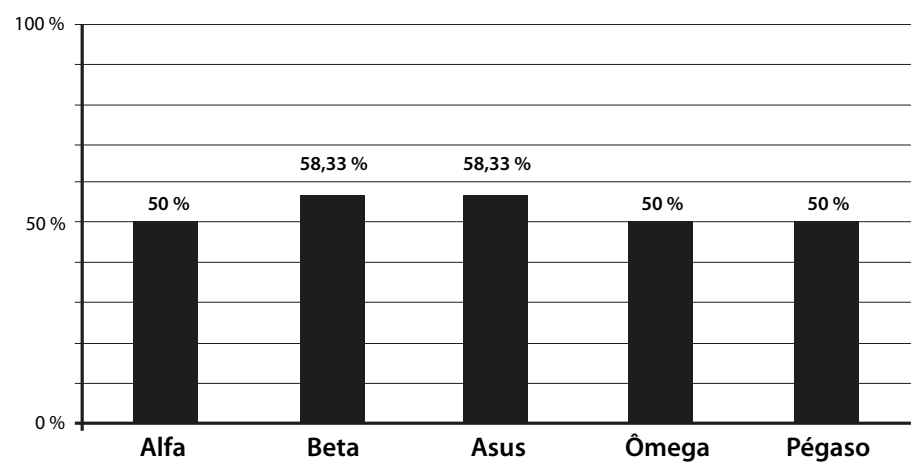

Fonte: Dados obtidos pelos pesquisadores em visita aos campi.

Os cinco campi pesquisados obtiveram 32 pontos nesse eixo. Ao se multiplicarem 04 pontos, pontuação máxima possível de ser alcançada em cada pergunta, pelo número de questões aplicadas em todos os campi, 15 questões, chega-se a um total máximo de 60 pontos. Os 32 pontos obtidos pelos campi correspondem a 53,3\% desse valor, o que pode ser representado pelo conceito "bom". Portanto, pode-se dizer que os campi do IFMG que foram investigados possuem formação inicial e continuada, destinada a professores e técnicos, que, embora se enquadre na categoria "boa", está mais próxima da categoria imediatamente inferior, ou seja, "razoável".

Os Campi Alfa, Ômega e Pégaso obtiveram um resultado inferior aos demais, principalmente devido à ausência de formação continuada para a gestão de sistemas educacionais e para o combate à evasão e à reprovação. Esses três campi não possuem nenhum tipo de formação continuada destinada aos gestores, para que coordenem o preenchimento e uso de sistemas de gestão educacional, como o Sistema Nacional de Informações da Educação Profissional e Tecnológica (SISTEC) e o Educacenso.
Esses três campi também não possuem nenhum tipo de formação continuada, destinada a professores e técnicos administrativos em educação, sobre evasão e reprovação. Essas unidades, no que se refere principalmente à evasão, não dispunham de uma pesquisa sistematizada que pudesse demonstrar os reais motivos que levam os estudantes a abandonarem o curso.

A reprovação e a evasão são dois grandes desafios da educação profissional e, por isso, precisam ser alvo de discussões que possam contribuir para a redução do índice de alunos que ficam retidos ou desistem do curso. Segundo Dore e Luscher (2011), a evasão é um fenômeno complexo e influenciado por um conjunto de fatores relacionados tanto ao estudante e à sua família quanto à escola e à comunidade em que o discente vive. $\mathrm{E}$ a despeito de ser um fenômeno complexo, ainda é pouco estudada. Mais uma vez é importante ressaltar a necessidade de se estudarem os fatores que levam à evasão escolar, especialmente aqueles localizados no interior da própria instituição escolar:

\begin{abstract}
O resultado do monitoramento da evasão no PEP é inequívoco quanto à necessidade de aprofundar o conhecimento das causas da evasão estudantil e de desenvolver medidas capazes de evitar o problema. (...) Para além dos fatores individuais, a identificação e a análise dos fatores intraescolares que intervêm nos processos de evasão são dimensões que não podem ser desconsideradas na implantação e avaliação da política pública para o ensino técnico, seja no plano federal, estadual ou municipal (DORE e LUSCHER, 2011, pgs. 785 e 786).
\end{abstract}

Os Campi Beta e Asus receberam uma nota um pouco melhor nesse eixo, 58,33\%, porque o primeiro respondeu que já realizou cursos de formação continuada para os professores sobre evasão e reprovação; e o segundo respondeu que já foi ofertada formação continuada para os gestores da unidade sobre a gestão de sistemas educacionais.

Os campi investigados não receberam uma nota menor nesse eixo porque todos responderam a uma pergunta, a qual tratava do índice de professores cuja graduação não se relaciona diretamente com a disciplina que leciona, dizendo que praticamente não há professores nessa situação. Todos os cinco campi disseram que o índice de professores cuja graduação não se relaciona diretamente com a disciplina que leciona encontra-se entre 0 a $10 \%$, ou seja, é muito bom. Esse índice pode ser considerado de fato como muito positivo, pois, como se sabe, a educação profissional ainda possui sérios problemas com relação à formação inicial de professores. Nesse sentido, segundo a Sinopse do Professor de 2009, existem 58.898 professores em atividade na educação profissional técnica de nível médio. Destes, apenas 
59,0\% possuíam licenciatura; 11,8\% sem curso superior concluído; $11,7 \%$ com somente o ensino médio e $0,07 \%$, o ensino fundamental (BRASIL, 2009).

A análise desse eixo evidencia que os campi investigados ainda não estão promovendo uma efetiva formação inicial e continuada para seus trabalhadores nas temáticas indicadas, embora apenas de 0 a $10 \%$ dos docentes possuem graduação não condizente com a(s) disciplina(s) que leciona.

A ausência de formação, especialmente a inicial, é grave e condiz com a constatação de vários pesquisadores (Filho e Shiroma, 2011; Machado, 2011; e Urbanetz, 2012).

De acordo com Saviani (2009), a primeira manifestação explícita de preocupação do Poder Público com a formação de professores no Brasil ocorreu em 15 de outubro de 1827, com a promulgação da Lei das Escolas de Primeiras Letras, lei esta que determinava que o ensino deveria se dar a partir do método mútuo.

A partir de 1834, com a promulgação do Ato Adicional, começa a ser instalado nas províncias um modelo escolar já conhecido no continente europeu: as Escolas Normais. A primeira, segundo o autor, foi a da Província do Rio de Janeiro, em 1835. O objetivo de tais escolas era preparar professores para a escola primária. Para isso, ensinava-se o mesmo currículo das escolas de primeiras letras. Pressupunha-se que os professores deveriam ter o domínio daqueles conhecimentos que iriam ensinar, não se dando muita importância ao conhecimento didático-pedagógico. Esse modelo escolar de formação de professores ganhou força e se expandiu muito no final do século XIX e início do XX, especialmente no período de 1890 a 1932 (SAVIANI, 2009).

No período de 1932 a 1939, um outro modelo de formação de professores surgiu no país: os Institutos de Educação. Conforme Saviani (2009), os institutos de educação foram concebidos como espaços de cultivo da educação, associando a pesquisa ao ensino. Eles foram pensados e organizados de maneira a incorporar as exigências da pedagogia, que buscava se firmar como um conhecimento de caráter científico.

De 1939 a 1971, segundo Saviani (2009), houve a criação dos cursos de pedagogia, das licenciaturas e o estabelecimento do padrão das escolas normais. Nesse período, segundo Gatti (2010), a partir da formação de bacharéis nas poucas universidades existentes, acrescentou-se mais um ano na formação desses profissionais com disciplinas voltadas para a educação, as quais dariam o direito ao bacharel à obtenção do diploma de licenciado. Esse recurso para a formação de professores ficou conhecido como "esquema 3+1". Gatti (2010) esclarece que inclusive o curso de pedagogia, regulamentado em 1939, passou por essa reformulação. Inicialmente, o curso formava bacharéis para atuarem nas delegacias de ensino e tinha duração de três anos. Mas, posteriormente, com a necessidade de professores para as escolas normais, o curso de pedagogia passou a contar com mais um ano de "conhecimentos pedagógicos" para a formação do licenciado. Foi nesse período, segundo Saviani (2009), que se iniciou uma concepção na formação de professores brasileiros que seria uma marca presente até os dias atuais: a valorização dos conhecimentos específicos de cada disciplina em detrimento dos saberes voltados à docência. Nas palavras do autor:

(...) tanto os cursos normais como os de licenciatura e Pedagogia centraram a formação no aspecto profissional garantido por um currículo composto por um conjunto de disciplinas a serem frequentadas pelos alunos, dispensada a exigência de escolas-laboratório. Essa situação, especialmente no nível superior, expressou-se numa solução dualista: os cursos de licenciatura resultaram fortemente marcados pelos conteúdos culturais-cognitivos, relegando o aspecto pedagógico-didático a um apêndice de menor importância, representado pelo curso de didática, encarado como uma mera exigência formal para a obtenção do registro profissional de professor (SAVIANI, 2009, p. 147).

A partir da década de 1970, segundo Saviani (2009), especialmente com a Lei 5.692/71, as Escolas Normais foram substituídas pela exigência do $2^{\circ}$ grau para o magistério no $1^{\circ}$ grau. Por meio do Parecer n 349/72, a habilitação específica do magistério foi organizada em duas modalidades básicas: uma com a duração de três anos, que habilitaria a lecionar até a $4^{\text {a }}$ série; e outra com a duração de quatro anos, habilitando ao magistério até a $6^{a}$ série do $1^{\circ}$ grau. $\mathrm{O}$ antigo curso Normal foi substituído por uma habilitação profissional, uma habilitação entre tantas outras existentes no período. Segundo o autor, para as quatro últimas séries do ensino de $1^{\circ}$ grau e para o ensino de $2^{\circ} \mathrm{grau}$, a LDB 5.692/71 previu a formação de professores em nível superior, em cursos de licenciatura curta (3 anos de duração) ou plena (4 anos de duração). Ao curso de Pedagogia, além da formação de professores para habilitação específica de Magistério, conferiu-se a atribuição de formar os especialistas em Educação, aí compreendidos profissionais como orientadores educacionais, supervisores escolares, diretores e inspetores. O autor esclarece ainda que, paralelamente a esse reordenamento da formação de professores, surgiu nos anos 80 um movimento de crítica à formação de professores. Esse movimento reivindicava a docência como base para a formação de todos os profissionais da educação. 
Com a LDB de 96, Lei nº 9.394/96, bem como com as Diretrizes Curriculares Nacionais para a Formação de Professores, Resolução CNE/CP nº 01/2002, assistiu-se à manutenção da supervalorização dos conhecimentos específicos, em detrimento dos didático-pedagógicos, além de uma concepção de formação fragmentada, tendo como locus diferentes instituições: institutos superiores de educação, escolas normais superiores, faculdades isoladas, centros universitários etc., quase sempre privados (GATTI, 2010).

A precariedade e a inconsistência didático-pedagógicas, constatadas na formação de professores para a educação básica, também podem ser observadas na educação profissional. Nesta, segundo Machado (2008 e 2011), a formação tem se caracterizado, historicamente, por arranjos emergenciais e improvisos, quase sempre voltados para professores que já atuam na modalidade. Essa autora esclarece que ainda se contratam professores para a educação profissional baseando-se apenas em sua formação específica e em sua experiência prática, acreditando-se que esses sujeitos se tornarão professores com o passar do tempo e por meio do autodidatismo. Ainda são poucos os cursos de licenciatura voltados para a formação de professores para a educação profissional.

No Instituto Federal de Minas Gerais, realidade investigada, por exemplo, não há nenhum programa ou iniciativa voltada para a formação de professores, especialmente para aqueles que fizeram curso de bacharelado. O que existe são indicações de cursos ofertados por outras instituições, especialmente da própria Rede, como o CEFET MG, conhecidos como "cursos de complementação pedagógica".

Atualmente, de acordo com Machado (2008), pode-se dizer que a formação de professores para a educação profissional no Brasil ocorre por meio das seguintes estratégias:

1. programas especiais de formação pedagógica (são os chamados "cursos de complementação pedagógica");

2. realização de cursos de pós-graduação lato sensu, de caráter pedagógico;

3. reconhecimento total ou parcial dos saberes profissionais de docentes, com mais de 10 (dez) anos de efetivo exercício no magistério da Educação Profissional;

4. por meio de uma segunda licenciatura,diversa da graduação original do professor, a qual o habilitará ao exercício docente.
Ou seja, até o momento, praticamente não há cursos de graduação na modalidade licenciatura destinados à formação de professores para atuarem na educação profissional (MACHADO, 2008). O que se vê são profissionais graduados nos mais diferentes cursos de bacharelado (economia, administração, ciências contábeis, ciências da computação, engenharia, etc.) que se utilizam das opções acima citadas para adquirirem um conhecimento pedagógico capaz tanto de atender às exigências da legislação quanto de responder às demandas colocadas pela atividade de ensino.

Embora não defendam explicitamente a constituição de cursos de licenciatura voltados para a formação de professores para a educação profissional, Furtado e Santos (2011), em trabalho que investigou a trajetória da formação dos professores para a educação profissional, observaram, assim como Machado (2008 e 2011), que não há, até hoje, uma proposta realmente consistente em relação à formação humanista e crítica dos professores dessa modalidade. Pelo contrário, ainda permanece o aspecto do profissional técnico em sala de aula, evidente desde o início desse ensino nas Escolas de Aprendizes e Artífices, bem como o aspecto do "profissional técnico professor". Para essas autoras, embora nos últimos anos as discussões a esse respeito tenham se intensificado, não se evidenciaram ainda políticas públicas incisivas e contínuas, no sentido da oferta para esse professor de licenciaturas com formação pedagógica crítica e reflexiva, possibilitando-lhe ter uma visão mais ampla do que tem a oferecer a seus alunos.

Além da ausência de políticas públicas voltadas para a formação de professores para a educação profissional, a própria Academia ainda não tem dado muita atenção à questão. Nesse sentido, por exemplo, Urbanetz (2012), em trabalho oriundo de sua tese de doutorado, argumenta que são quase inexistentes pesquisas sobre a temática "formação docente para a educação profissional" e que isso ocorreria justamente pela ausência de políticas públicas preocupadas com a formação de professores.

\section{Estágio e Trabalho de Conclusão DE CURSO}

Esse eixo possuía 3 questões: integração do curso com o setor produtivo para fins de estágio curricular, presença do Trabalho de Conclusão de Curso (TCC) e efetividade no processo de orientação e elaboração do TCC. Essa última pergunta só foi utilizada para aqueles campi que responderam possuir o TCC. Os resultados obtidos pelos campi, nesse eixo, estão descritos no Gráfico 3. 
Gráfico 3 - Estágio e trabalho de conclusão de curso.

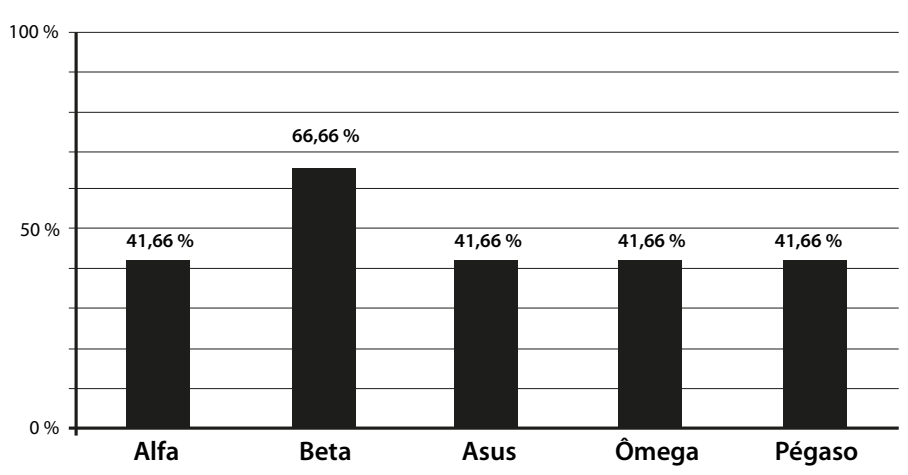

Fonte: Dados obtidos pelos pesquisadores em visita aos campi.

Os cinco campi pesquisados obtiveram 28 pontos no Eixo 3. Esse eixo, como já mencionado, continha 2 questões para os campi que não possuíam em seus cursos técnicos o TCC (Alfa, Asus, Ômega e Pégaso) e 3 questões para o campus que possuía em seus cursos técnicos o TCC (Beta). Dessa forma, ao se multiplicarem 04 pontos, pontuação máxima possível de ser alcançada em cada pergunta, pelo número de questões aplicadas em todos os campi, 11 questões, chega-se a um total máximo de 44 pontos. Os 28 pontos obtidos pelos campi correspondem a 63,63\% desse valor, o que pode ser representado pelo conceito "bom".

No Campus Beta, no que se refere à questão sobre a integração do curso com o setor produtivo para fins de estágio curricular, os gestores informaram que ainda não houve uma efetiva integração, embora existam alguns convênios. Há parceria com o Centro de Integração Empresa Escola (CIEE) para todos os cursos técnicos. Esses gestores relataram que existem convênios com algumas empresas da região e que o campus é que procura tais empresas. Disseram que as empresas não têm interesse em ter estagiários para não arcar com os custos previstos na nova legislação do estágio, Lei $n^{\circ} 11.788$, de 25 de setembro de 2008, art.12 (BRASIL, 2008a). Nessa unidade, o estágio é opcional, embora os gestores tenham sinalizado a intenção de torná-lo obrigatório.

Sobre o Trabalho de Conclusão de Curso, no Campus Beta, os gestores relataram que há TCC em todos os cursos técnicos desse campus. Essa característica foi exatamente a que proporcionou ao Campus Beta uma nota superior à dos demais. Nesse campus, todos os trabalhos são orientados pelos professores, mas a quantidade de docentes não é considerada suficiente. Acerca da efetividade no processo de orientação e elaboração do Trabalho de Conclusão de Curso, os gestores disseram que as orientações têm sido razoavelmente efetivas, especialmente porque os alunos não têm professores em quantidade suficiente para orientá-los.
Nos demais campi, o estágio supervisionado não é obrigatório, com exceção do curso Técnico em Metalurgia do Campus Asus, no qual tal atividade é obrigatória. Entre esses campi, observou-se que dois ainda precisam estabelecer parcerias e convênios mais efetivos com empresas da região para que seus alunos possam realizar o estágio: Alfa e Pégaso.

Entre os campi pesquisados, a realização do TCC em cursos técnicos não é obrigatória, com exceção do Campus Pégaso. Nesse campus, inclusive, há um trabalho de conclusão de curso bastante inovador, o Trabalho de Avaliação Interdisciplinar, realizado no curso Técnico em Administração, modalidade concomitante. Esse trabalho equivale ao TCC e consiste na resolução de uma situaçãoproblema real encontrada em uma empresa, de forma conjunta, entre aluno e professores.

Acerca da efetividade no processo de orientação e elaboração do Trabalho de Conclusão de Curso no Campus Pégaso, as gestoras disseram que existe uma disciplina de "Projeto Orientado", cujo professor realiza as orientações gerais aos alunos. Além disso, há um professor orientador para cada TCC. As gestoras informaram que o resultado da primeira experiência não foi bom e que percebem a necessidade de definir um horário para a orientação, de modo a deixar a atividade mais sistematizada. Além disso, o tempo de realização do TCC, quatro meses, foi considerado curto.

Além dos poucos convênios realizados entre os campi investigados e o setor produtivo, é problemática a ausência de obrigatoriedade de realização de estágio e TCC. O estágio, principalmente, constitui-se em uma oportunidade para o aluno vivenciar o cotidiano de uma instituição, bem como mobilizar os conhecimentos aprendidos. É uma atividade que não pode, por um lado, ser confundida com a "venda da força de trabalho" e, por outro, com a realização de atividades de menor prestígio e muitas vezes desvinculadas daquilo que se aprendeu na escola. Nesse sentido, segundo Pacheco (2012, p. 102), o estágio:

Trata-se de um dos mais importantes momentos de integração dos conhecimentos trabalhados na escola a partir da prática. Jamais deve ser confundido com emprego. Mesmo ocorrendo no ambiente de trabalho, é estritamente um momento de formação orientada e supervisionada, necessariamente previsto no projeto do curso. Por mais próximo que seja esse momento formativo da realidade de trabalho do profissional, é ainda uma simulação do real, pois a relação do estudante estagiário com a parte concedente do estágio é diversa da estabelecida entre empregado e empregador. A primeira é caracterizada pela oportunidade educacional de contextualização curricular através da prática. A segunda, pela venda da força de trabalho. 
Nesse sentido, de acordo com Felício e Oliveira (2008), o estagiário deveria ser concebido como autor da sua formação profissional. Para esses autores, deve-se entendê-lo como um sujeito no seu processo de formação, capaz de se transformar num profissional reflexivo e desenvolver competências investigativas que o levem a compreender a realidade em que está atuando, almejando-se que ele assuma uma posição crítica em relação ao contexto em que exerce sua atividade e que se emancipe das situações que podem inibir a sua prática profissional e impedir o seu desenvolvimento pessoal.

Os cursos técnicos têm, fundamentalmente, um caráter profissionalizante. Portanto, não exigir a realização dessa atividade para a conclusão do curso pode dificultar a aprendizagem do saber-fazer específico das profissões, aprendizagem essa proporcionada muitas vezes no exercício do estágio.

\section{ELEMENTOS CONCLUSIVOS}

A avaliação da educação profissional técnica de nível médio realizada nos novos campi do IFMG indicam que a organização didático-pedagógica, a formação inicial e continuada e o estágio curricular e TCC foram bem avaliados. Contudo, há aspectos preocupantes nesses três eixos avaliados.

A organização didático-pedagógica dos campi obteve notas positivas em todas as unidades, com exceção do Campus Beta, que recebeu o conceito "razoável". Entretanto, vale salientar que, apesar do conceito "bom", melhorias mostram-se necessárias na maioria dos campi no que se refere à matriz curricular dos cursos, às metodologias de ensino empregadas pelos professores, à diversidade das estratégias didático-metodológicas, à interdisciplinaridade e à realização de atividades complementares, além de ser necessário aperfeiçoar o processo de aproveitamento de conhecimentos e experiências anteriores. Esses aspectos necessitam ser repensados com urgência, pois, como demonstraram as pesquisas de Dore e Luscher (2011), questões pedagógicas, de responsabilidade da escola, possuem um importante papel na decisão do aluno de curso técnico de abandonar a escola.

Embora a formação inicial e continuada tenha recebido o conceito "bom", a pontuação encontra-se próxima do conceito "razoável". Nesse eixo, praticamente não houve diferenças entre os campi. Os resultados mostram que são necessárias ações para incrementar as formações direcionadas aos professores, técnicos e gestores. Como já foi discutido por autores como Machado (2008 e 2011),
Furtado e Santos (2011), há de se pensar em alternativas consistentes para a formação de professores para atuarem na educação profissional. É tempo de reverter a lacuna deixada pela ausência do Estado em matéria de políticas públicas voltadas para a formação desses professores.

Sobre o estágio curricular e o trabalho de conclusão de curso, embora esses itens tenham recebido o conceito "bom", isoladamente, 4 campi receberam o resultado "razoável". Destaca-se o fato de que, apesar de haver possibilidade de realização de estágio, apenas no curso de Metalurgia essa atividade é obrigatória. A não obrigatoriedade do estágio na grande maioria dos cursos é preocupante, uma vez que o estágio constitui-se em uma oportunidade importante para os alunos vivenciarem situações reais de trabalho e aprenderem o saber-fazer próprio das profissões em que estão se formando (FELíCIO e OLIVEIRA, 2008).

Quanto ao TCC, há esse trabalho em dois campi - Beta e Pégaso. No primeiro, de maneira generalizada; no segundo, em apenas um curso. Em três campi não há - Alfa, Asus e Ômega.

Enfim, observa-se que, embora os novos campi do IFMG tenham obtido resultados satisfatórios nos três eixos analisados, especialmente do ponto de vista quantitativo, vários aspectos desses eixos necessitam de melhorias, demonstrando que outras pesquisas, com cunho qualitativo, fazem-se importantes para a avaliação de cursos técnicos dos Institutos Federais. Nesse sentido, espera-se que o estudo realizado possa contribuir para o desenvolvimento de outras investigações a respeito dos Institutos Federais de Educação, Ciência e Tecnologia, especialmente sobre questões ainda problemáticas e que representam desafios para essas instituições.

\section{REFERÊNCIAS}

BRASIL. Ministério da Educação. Conselho Nacional de Educação. Resolução CNE/CEB nº 06, de 20 de setembro de 2012. Define Diretrizes Curriculares Nacionais para a Educação Profissional Técnica de Nível Médio. Diário Oficial da União, Poder Executivo, Brasília, DF, 21 de set. 2012. Seção 1, p. 22.

\section{Um novo modelo em educação}

profissional e tecnológica: concepção e

diretrizes, Brasília, 2010. Disponível em: <http:// portal.mec.gov.br/index.php?option=com content \&view $=$ article\&id=12503\&ltemid $=841>$ Acesso em: 23 mai 2014. 
Ministério da Educação. Instituto Nacional de Estudos e Pesquisas Educacionais (INEP). Sinopse do Professor: 2009. Brasília, DF, MEC, INEP, 2009. Disponível em: http://portal.inep.gov.br/basica-censoescolar-sinopse-sinopse Acesso em 23 de maio de 2014.

Lei $n^{\circ} 11.788$, de 25 de setembro de 2008. Dispõe sobre o estágio de estudantes; altera a redação do art. 428 da Consolidação das Leis do Trabalho - CLT, aprovada pelo Decreto-Lei no 5.452, de 10 de maio de 1943, e a Lei no 9.394, de 20 de dezembro de 1996; revoga as Leis nos 6.494, de 7 de dezembro de 1977, e 8.859, de 23 de março de 1994, o parágrafo único do art. 82 da Lei no 9.394, de 20 de dezembro de 1996, e o art. 6 o da Medida Provisória no 2.164-41, de 24 de agosto de 2001; e dá outras providências. Diário Oficial da União, Poder Executivo, Brasília, DF, 26 de set. 2008a. Seção 1, p. 3.

Lei $n^{\circ} 11.892$, de 29 de dezembro de 2008. Institui a Rede Federal de Educação Profissional, Científica e Tecnológica, cria os Institutos Federais de Educação, Ciência e Tecnologia, e dá outras providências. Diário Oficial da União, Poder Executivo, Brasília, DF, 30 de dez. 2008b. Seção 1, p. 1.

CALDAS, L. et. al. Institutos Federais: Lei n 11.892 de 29/12/2008 - Comentários e reflexões. In: PACHECO, E. (Org.). Institutos Federais: uma revolução na educação profissional e tecnológica. Fundação Santillanna/ Moderna: Brasília, São Paulo, 2011. p. 47-113.

DORE, R. e LUSCHER, A Z. Política educacional no Brasil: educação técnica e abandono escolar. Políticas, sociedade e educação, Brasília, supl. 1, v. 8, p. 147-176, dez. 2011.

FELíCIO, H. M. dos S.; OLIVEIRA, R. A. de. A formação prática de professores no estágio curricular. Educar, Curitiba, n. 32, p. 215-232, 2008.

FILHO, D. L. L.; SHIROMA, E. O. Trabalho docente na educação profissional e tecnológica e no PROEJA. Educação e Sociedade, Campinas, v. 32, n. 116, p. 725743, jul.-set, 2011.

FURTADO, E. D. P.; SANTOS, S. de F. R. O professor da educação profissional: desafios nas práticas pedagógicas. Boletim Técnico do Senac: a revista da educação profissional, Rio de Janeiro: Senac, v. 37, nº 1, p. 60-71, jan./abr. 2011.
GATTI, B. A. Formação de professores no Brasil: características e problemas. Educação e Sociedade, Campinas, v. 31, n. 113, p. 1355-1379, out.-dez. 2010.

IFMG. Resolução nº 041, de 03 de dezembro de 2013. Dispõe sobre a aprovação do Regimento de Ensino do Instituto Federal de Educação, Ciência e Tecnologia de Minas Gerais. Boletim de Serviço do IFMG, Belo Horizonte, n 57, p. 148-183, dez. de 2013.

MACHADO, L. R. de S. O desafio da formação dos professores para a EPT e PROEJA. Educação e Sociedade, Campinas, v. 32, n. 116, p. 689-704, jul./set. 2011. Diferenciais inovadores na formação de professores para a educação profissional. Revista Brasileira da Educação Profissional e Tecnológica, v. 1, p. 8-22, 2008

NETO, A. C. dos S. Da Escola de Aprendizes ao Instituto Federal de Sergipe: 1909 - 2009, Revista Brasileira da Educação Profissional e Tecnológica, Brasília, MEC, SETEC, v. 2, n. 2, p. 25-39, nov. 2009.

PACHECO, E. (Org.). Perspectivas da educação profissional técnica de nível médio: proposta de Diretrizes Curriculares Nacionais. São Paulo: Fundação Santillanna/ Moderna, 2012.

SAVIANI, D. Formação de professores: aspectos históricos e teóricos do problema no contexto brasileiro. Revista Brasileira de Educação, Campinas, v. 14, n 40, p. 143155, jan./abr. 2009.

SILVA, L. P. da. Formação profissional no Brasil: o papel do Serviço Nacional de Aprendizagem Industrial - SENAI. História, v.29, n.1, p. 394-417, 2010.

URBANETZ, S. T. Uma ilustre desconhecida: a formação docente para a educação profissional. Revista Diálogo Educacional, Curitiba, v. 12, n. 37, p. 863-883, set./dez. 2012.

Recebido em: 31/01/2014

Aceito em: 29/08/2014 